Research Article

\title{
Morphology and damage mechanism of lignocellulosic fruit fibers reinforced polymer composites: a comparative study
}

\author{
B. NagarajaGanesh ${ }^{1}$ (D) B. Rekha ${ }^{2}$
}

() Springer Nature Switzerland AG 2019

\begin{abstract}
This study exhibits and compares the damage mechanism and mechanical properties of the polymer composites reinforced with dry and matured fruit fibers obtained from Cocos nucifera and Luffa cylindrica fruits respectively. Composite samples are prepared using polyester resin and different weight proportion of these fibers ranging from 10 to $40 \mathrm{wt} \%$ in intervals of $10 \mathrm{wt} \%$ with random fiber orientation involving hand layup technique. Studies prove that the composites containing $30 \mathrm{wt} \%$ of the fibers exhibit optimum mechanical properties. The maximum flexural strength and impact strength of the Cocos nucifera composites obtained is $27 \mathrm{MPa}$ and $12.22 \mathrm{~kJ} / \mathrm{m}^{2}$ whereas the corresponding values are $30 \mathrm{MPa}$ and $24.88 \mathrm{~kJ} / \mathrm{m}^{2}$ for Luffa cylindrica composites. Load versus Deflection curve obtained for Cocos nucifera composites exhibit non-catastrophic failure with increased percent elongation showing the slow and steady ductile failure. On the contrary, Luffa cylindrica composites exhibit catastrophic failure with sudden abrupt brittle fracture. Fractured samples are examined to show the failure mode through scanning electron microscope and are reported.
\end{abstract}

\section{Graphic abstract}

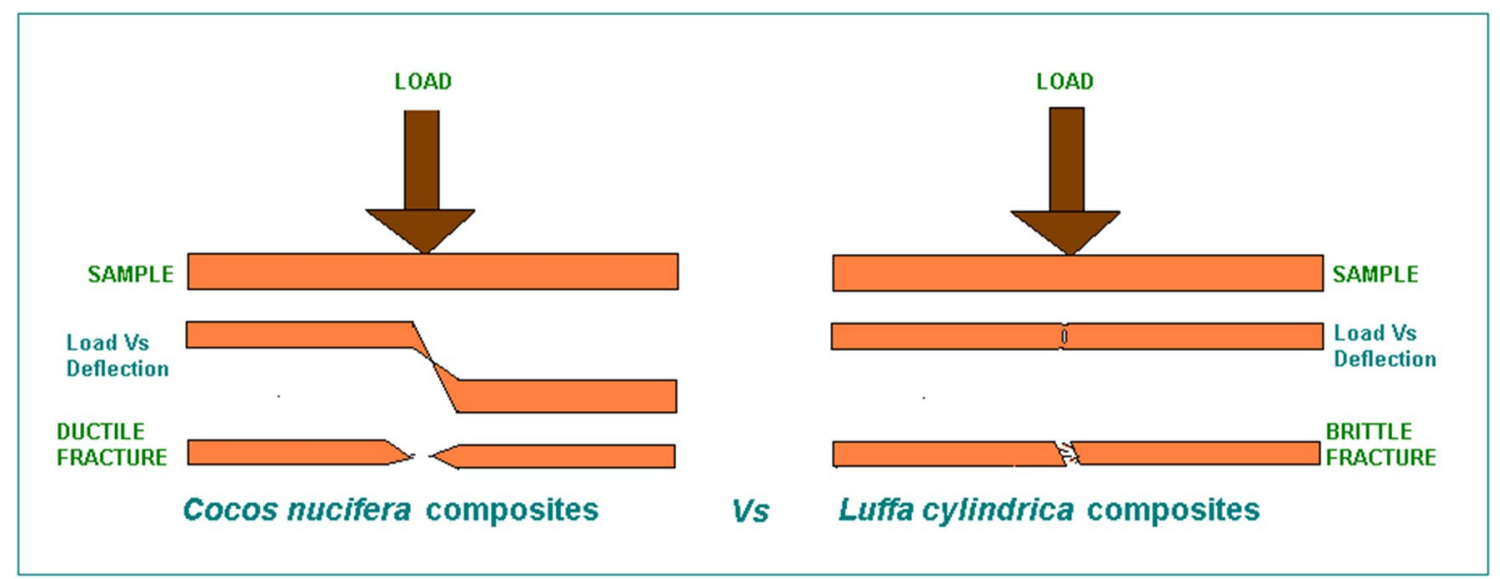

Constituent fibers in the composites reinforce the polymers and also determine the mechanical behaviour of the composites

Keywords Cellulose fibers · Polymer composites · Mechanical properties · Damage mechanism · Fractured samples morphology

$\triangle$ B. NagarajaGanesh, bng9@ymail.com | 'Department of Mechanical Engineering, Madurai Institute of Engineering and Technology, Pottapalayam, Sivagangai District, Tamil Nadu, India. ${ }^{2}$ Research Scholar, Department of Physics, Manonmaniam Sundaranar University, Tirunelveli, Tamil Nadu, India. 


\section{Introduction}

Natural fibers receive considerable attention as polymer reinforcements on account of their biodegradable characteristics and specific mechanical properties. Many researches are currently taking place in this domain in search of new fibers that could be used to produce ecofriendly industrial components owing to their abundant availability, ecological properties, less production cost, minimal tool wear and low energy requirement are some major reasons that make the cellulose based natural fibers as reinforcements for polymer matrix composites, thereby reducing the dependence of synthetic fibers [1-3]. Stiffness requirements for light and non-structural applications, thermal, vibro-acoustic properties for the manufacture of automobile interiors, door panels are achieved by the natural based materials [4]. The mechanical properties of the composites reinforced with natural fibers largely depend on the constituent fibers, their polarity, matrix and interfacial adhesion that exist between the matrix and fibers [5]. Fibers are the load bearing elements in the composites and the weight or volume proportion of the fibers in the composite system is an important parameter in determining the mechanical properties of the composite. In addition, fiber length, fiber structure and chemical composition too play a vital role in reinforcing the polymers.

Many researches are conducted in exemplifying the influence of fiber content in the composites. In a study on banana fiber reinforced polyester composites, it was initially observed that increasing fiber loading caused a decline in mechanical strength as compared to the neat composite. However, when the fiber loading was made greater than $19 \%$, an increase in the values was found for optimum mechanical properties at a fiber volume of $40 \%$ [6]. A study with Cocos nucifera fibers reinforced polyester composites made using hand layup technique showed maximum flexural strength at $30 \%$ and the increasing trend in mechanical properties ceased when the proportion of fibers in the system exceeded $30 \mathrm{wt} \%$ as a result of poor interfacial adhesion at higher fiber loading [7]. In using hemp fibers as polyester resin reinforcement, it was proved that increasing fiber proportion leads to increase in mechanical properties of the composites and the trend ceased when the fiber content was increased to $40 \%$. Also, noticed is the increase in the moisture uptake of fibers leading to micro-cracks in the matrix [8]. In an interesting study on using agricultural residue, rice straw fibers reinforced polyester composites proved that fiber volume of $40 \%$ and above exhibited enhanced flexural strength and impact strength than the control composites [9]. Kenaf bast fibers reinforced polyester composites have showed that $20 \mathrm{wt} \%$ fibers resulted in good tensile and flexural properties, while $10 \mathrm{wt} \%$ of kenaf bast fibers resulted in good impact strength [10]. Yoganandam et al. [4] have fabricated composites using handlayup technique with fibers extracted from Calotropis procera stem as reinforcements. The mechanical properties of the composites are seen to increase with increasing fiber content and maximum flexural, impact strength of the polyester composites are obtained for composites containing 30 $w t \%$ of fibres. In a study to determine the effect of composite fabrication technique on the mechanical properties of the sisal-leaf fibers reinforced polyester composites, resin transfer moulding was found to produce mechanically stronger composites than compression moulding on account of their better wettability and less void content [11]. It was asserted that higher void content resulted in higher water absorption. A maximum flexural strength of $47 \mathrm{MPa}$ and a maximum flexural modulus of 3.09 MPa were achieved for unidirectionally oriented Grewia serrulata fibers reinforced polyester composites prepared using cold compression technique [12]. In an examination to find the optimum fiber length of using hemp fibers as reinforcements, fiber lengths varying between 20 and $70 \mathrm{~mm}$ were used. It was shown that $30 \mathrm{~mm}$ fiber length is the optimum length to produce composites of good mechanical properties and fiber lengths exceeding $30 \mathrm{~mm}$ led to fiber entanglements [13]. All the above studies show that the natural fibers reinforce polymers with increasing mechanical properties on increasing the fiber content. The relative weight/volume\% along with fiber length and fabrication technique influences the mechanical properties of the polymer composites.

In this present study, the mechanical properties of the polymer composites reinforced by lignocellulosic fibers derived from dry and matured fruits of Cocos nucifera and Luffa cylindrica are tested and reported with special focus on their damage mechanism. Characterization studies conducted on these dry and matured fibers of Cocos nucifera and Luffa cylindrica fibers have shown that the fibers are potential enough to be used as reinforcements in polymers [14]. These fibers contain crystalline cellulose that makes them to be used as potential reinforcements. An idea of the damage mechanism of the composites can help designing a composite to avoid unprecedented failures. This study emphasizes the mechanical properties of the composites reinforced with cellulose based fibers derived from the mesocarp of the 
fruits and the damage mechanism, as a function of fiber content blended with the polymer resin.

\section{Experimental}

\subsection{Materials}

Dry and matured lignocellulosic fibers present in Cocos nucifera and Luffa cylindrica fruits are used for the study. Cocos nucifera fibers present between the hard internal shell of the coconut fruit and the mesocarp are collected after taking the matured coconut fruit. These fibers are leftovers and are discarded normally as landfills. Luffa cylindrica fruit after maturity becomes completely fibrous losing out its flesh and remains in the plant as a woven structure. Cocos nucifera fibers are brown in colour while Luffa cylindrica fibers are pale yellow in colour. These fibers are used to reinforce the polymer matrices in the present study. Initially, all the fibers are washed thoroughly with water to remove any impurities or dirt present in them and they are manually cut into $30 \mathrm{~mm}$ length using scissors so that they can be easily dispersed in the matrix during composite fabrication.

\subsection{Fiber parameters}

The extracted fibers of Cocos nucifera and Luffa cylindrica are cut using a steel razor into thin slices and the anatomical parameters of the individualized fibers such as fiber diameter, lumen diameter and cell wall thickness are observed under a light microscope made by Coslab, India without staining. Ten samples of fibers are considered for studying the fiber parameters and the average value is reported to maintain consistency.

\subsection{Sample preparation}

The Cocos nucifera fibers reinforced composite samples are prepared using dry and matured chopped Cocos nucifera fibers as reinforcement in unsaturated polyester resin. Similarly, Luffa cylindrica reinforced composite samples are prepared using Luffa cylindrica fibers as reinforcement and unsaturated polyester resin as matrix. Composites are prepared with methyl ethyl ketone peroxide (MEKP) as catalyst and cobalt napthenate as accelerator. A wooden mould of size $200 \mathrm{~mm} \times 200 \mathrm{~mm}$ is used to make specimens with different weight percentages of fibers ranging from 10 to $40 \%$ in steps of $10 \%$, at random fiber orientation to study the effect of fiber loading on the damage mechanism and mechanical properties of the composites.

\subsection{Characterization}

Flexural test is performed on the samples of size $150 \times 12.5 \times 3 \mathrm{~mm}$ according to ASTM D790 standards. In this 3 -point bending test, load is applied at three points in which the top layer, middle layer and bottom layer of the specimen is subjected to compression, shear and tension forces respectively. The samples are tested at a crosshead speed of $2 \mathrm{~mm} / \mathrm{min}$ by keeping the support span length as $50 \mathrm{~mm}$. The experiment is continued until the specimen breaks.

Impact test is performed using an Izod impact machine of $25 \mathrm{~J}$ capacity with unnotched samples of size $65 \times 15 \times 3 \mathrm{~mm}$ according to ASTM D256 standards. The effect of fiber loading on the resin is studied and the weight percentage of fiber that gives maximum impact strength is found from the energy absorbed by the specimen during fracture. In each case, five samples are tested and the average value is reported.

The morphology of the fractured surfaces of the samples is examined using a Scanning Electron Microscope (SEM) (Model: VEGA3 TESCAN) which is operated at $20 \mathrm{kV}$ at an appropriate working distance of about $10 \mathrm{~mm}$. Prior to SEM analysis, the samples are sputter coated with gold to avoid charging.

\section{Results and discussion}

\subsection{Fiber parameters}

The anatomical structure of the individualized Cocos nucifera and Luffa cylindrica fibers observed through the microscope shows the individualized fiber diameter, lumen, cell wall, lacuna etc. These parameters play a definite role as they control the properties of the fiber. The average individualized fiber diameter, lumen diameter and cell wall thickness of Cocos nucifera fibers is observed and measured as $22.53 \mu \mathrm{m}, 13.76 \mu \mathrm{m}$ and $4.29 \mu \mathrm{m}$ respectively. Similarly, the corresponding values of the Luffa cylindrica fibers are $18.27 \mu \mathrm{m}, 9.62 \mu \mathrm{m}$ and $5.10 \mu \mathrm{m}$ respectively. Lumen diameter is an important structural parameter of a fiber that persuades the strength of a fiber. Low lumen diameter of a fiber pronounces better mechanical strength than a fiber with higher lumen diameter [15]. The individualized fiber dimensions of some natural fibers are shown in the Table 1 [16-18].

\subsection{Studies on Cocos nucifera fibers reinforced composites}

\subsubsection{Flexural strength}

The ability of a material to withstand the longitudinally applied bending force is examined with the three point bending test in the present study. Tensile, compressive 
Table 1 Individualized fiber dimensions of some natural fibers

\begin{tabular}{llll}
\hline Fiber name & Diameter $(\mu \mathrm{m})$ & $\begin{array}{l}\text { Lumen } \\
\text { diameter } \\
(\mu \mathrm{m})\end{array}$ & $\begin{array}{l}\text { Cell wall } \\
\text { thickness } \\
(\mu \mathrm{m})\end{array}$ \\
\hline Kenaf & 22.10 & 12.70 & 4.30 \\
Panicum virgatum & 13.10 & 5.80 & 4.60 \\
Rice & 14.80 & 6.40 & 4.20 \\
Wheat & 13.21 & 4.02 & 4.59 \\
Eucalyptus grandis & 19.21 & 12.20 & 3.20 \\
Crotolarea pallida & 25.15 & 15.86 & 4.64 \\
Sida cordifolia & 22.74 & 14.00 & 4.37 \\
Vernonia cinerea & 22.59 & 14.09 & 4.25 \\
\hline
\end{tabular}

Table 2 Flexural strength of the Cocos nucifera fibers reinforced composites

\begin{tabular}{lll}
\hline $\begin{array}{l}\text { Weight percent- } \\
\begin{array}{l}\text { age of unsaturated } \\
\text { polyester resin }\end{array}\end{array}$ & $\begin{array}{l}\text { Weight percentage } \\
\text { of Cocos nucifera } \\
\text { fibers }\end{array}$ & $\begin{array}{l}\text { Flexural strength of } \\
\text { the composites (MPa) }\end{array}$ \\
\hline 90 & 10 & 20.6 \\
80 & 20 & 23.96 \\
70 & 30 & 27.10 \\
60 & 40 & 26.3 \\
\hline
\end{tabular}

and shear forces act on the specimen and the bending strength of the composite is determined. The flexural strength of the neat composite is found as $20 \mathrm{MPa}$. When the fiber loading is $10 \mathrm{wt} \%$, the composite shows a flexural strength of $20.6 \pm 0.36 \mathrm{MPa}$, a marginal increase in the flexural strength compared to the neat composite. This is due to the transfer of low loads from the matrix to the fibers. On further fiber loading, the flexural strength increases exhibiting an increasing trend and a maximum of $27 \pm 0.2 \mathrm{MPa}$ is obtained for the sample reinforced with $30 \mathrm{wt} \%$ of Cocos nucifera fibers which agrees with the previously published results [19-21] This increase is mainly due to the load bearing capacity of the fibers that receive the load from the matrix. On further fiber loading, there is a decline in the flexural strength values of the composites. The flexural strength of the composites for $10 \%, 20 \%, 30 \%$ and $40 \%$ fiber loading are shown in Table 2 . This shows that beyond certain limit, there is a decreasing trend noticed after the inclusion of fibers and is mainly due to the lack of adhesion between the fibers and matrix leading to weak dispersive forces $[22,23]$. When the fiber loading increases the matrix content becomes insufficient and the failure occurs on the specimen.

Figure 1 displays the Load versus Deflection curve obtained for the Cocos nucifera reinforced sample with varying weight proportion of the fibers. The curve obtained for the $10 \mathrm{wt} \%$ of fibers, shows a non-linear trend initially,

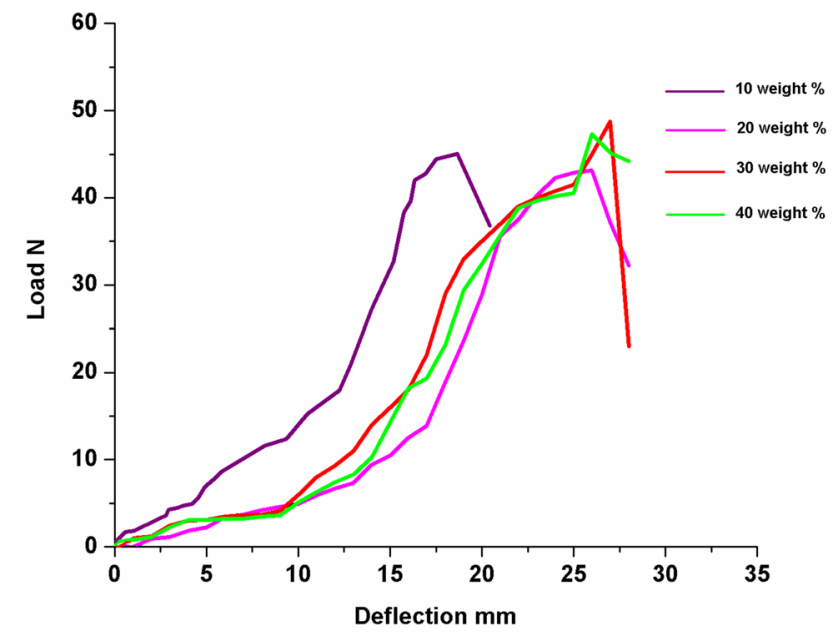

Fig. 1 Load versus Deflection sample curve for the different wt $\%$ Cocos nucifera nucifera fibers reinforced composites

as soon as the load is applied and the deflection is high compared to the load applied. The reason for this kind of behaviour is the elongation property of these fibers which is intrinsic and is due to the high microfibrillar angle of these fibers. Micro-fibrillar angle is an important structural parameter that signifies the angle of inclination of the cellulosic microfibrils present in the middle secondary layer of the plant cell wall $[15,16]$. High microfibrillar values result in more elongation of the fibers and hence its composites. Deflection continues till it reaches $4 \mathrm{~mm}$ for $4 \mathrm{~N}$ load followed by a knee in the graph. The deflection is more and this is attributed to the characteristic feature of the Cocos nucifera fibers which exhibit highest elongation property compared to other cellulosic fibers [24] which is shown in the SEM image in the present study. After that, there is an increase in the load where the deflection is $9 \mathrm{~mm}$ for $11 \mathrm{~N}$ load. Then, the Load versus Deflection is quite linear till $30 \mathrm{~N}$, thus exhibiting a linear behaviour after which there is a sudden increase in load for $14 \mathrm{~mm}$ deflection. At this stage, load applied is proportional to the deflection produced. Later, at a maximum load of $48.78 \mathrm{~N}$ the sample breaks with a deflection of $17.1 \mathrm{~mm}$. The sample fails in a less appalling manner which may be due to the failure of the specimen at the neutral axis denoting shear failure mode $[19,25]$.

Similarly, the load deflection curves obtained for different weight loadings of Cocos nucifera reinforced composites is also shown in Fig. 1. The load that the samples could withstand is $37.08,43.15,48.78$ and $47.34 \mathrm{~N}$ for $10,20,30$ and 40 weight proportion of fiber loading respectively. It can be seen that $30 \mathrm{wt} \%$ is the optimum fiber content in composites that can exhibit high flexural strength. This is similar to the mechanical behaviour of banana fibers reinforced polyester composites [26]. It can be seen that 


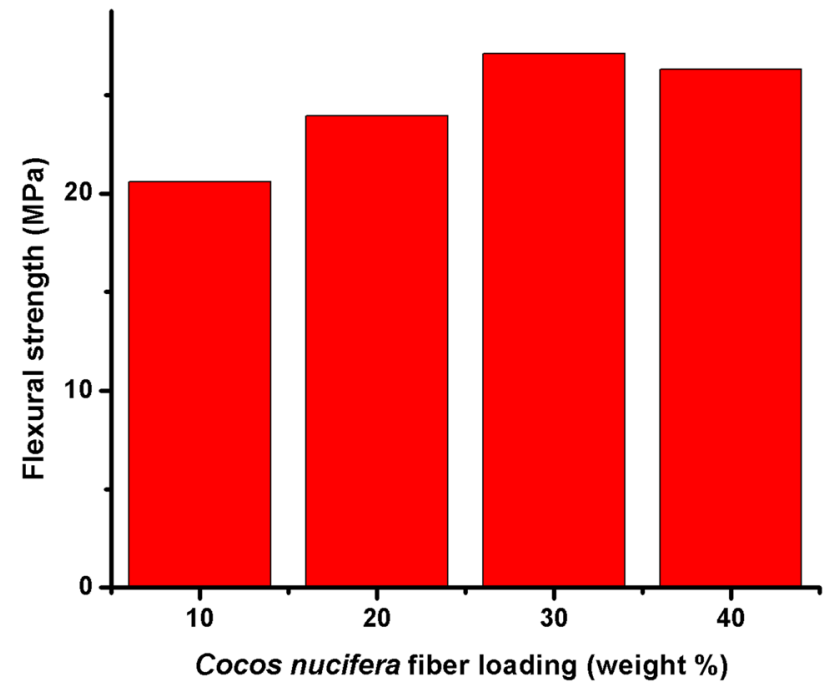

Fig. 2 Flexural strength of Cocos nucifera fibers reinforced composites

the area under the curve is high, which means that the samples are tough and is attributed to the increased resistance to crack propagation. This is in accordance with the hybrid composites reinforced using cellulose fibers and animal fibers reinforced composites [21]. Figure 2 shows the flexural strength of Cocos nucifera fibers reinforced composites for different fiber loadings. The increase in flexural strength on fiber loading is due to the increased bonding adhesion between fiber and matrix at higher fiber loading [26]. Kenaf bast fibers reinforced polyester composites have showed that $20 \mathrm{wt} \%$ fibers resulted in good flexural properties [10]. In order to increase the load bearing characteristic of this fiber, hybridization or some chemical treatments on these fibers can be done [27].

\subsubsection{Impact strength}

The toughness property of a material is found out using the impact strength of a composite. Matrix-fiber interface, fiber, matrix properties are the factors that control the impact strength of the composite. When a material is suddenly subjected to a force, the material absorbs energy due to the impact and this energy is dissipated by the material through fracture, fiber pull-outs and delamination which are considered as the common impact energy dissipation mechanisms [7]. The impact strength values of the composites reinforced with $10 \%, 20 \%, 30 \%$ and $40 \%$ of Cocos nucifera fibers are $10.22 \pm 0.14,10.67 \pm 0.16$, $12.22 \pm 0.3$ and $10.89 \pm 0.19 \mathrm{~kJ} / \mathrm{m}^{2}$ as shown in Table 3. This shows that the impact strength of the composites reinforced with Cocos nucifera fibers exhibit an increasing trend on increasing the fiber content as found by other researchers $[8,13,27]$. But when the fiber loading increases beyond
Table 3 Impact strength of Cocos nucifera reinforced composites

\begin{tabular}{lll}
\hline $\begin{array}{l}\text { Weight percentage of } \\
\text { unsaturated polyester resin }\end{array}$ & $\begin{array}{l}\text { Weight percentage of } \\
\text { Cocos nucifera fibers }\end{array}$ & $\begin{array}{l}\text { Impact } \\
\text { strength (kJ/ } \\
\left.\mathrm{m}^{2}\right)\end{array}$ \\
\hline 90 & 10 & 10.22 \\
80 & 20 & 10.67 \\
70 & 30 & 12.22 \\
60 & 40 & 10.89 \\
\hline
\end{tabular}

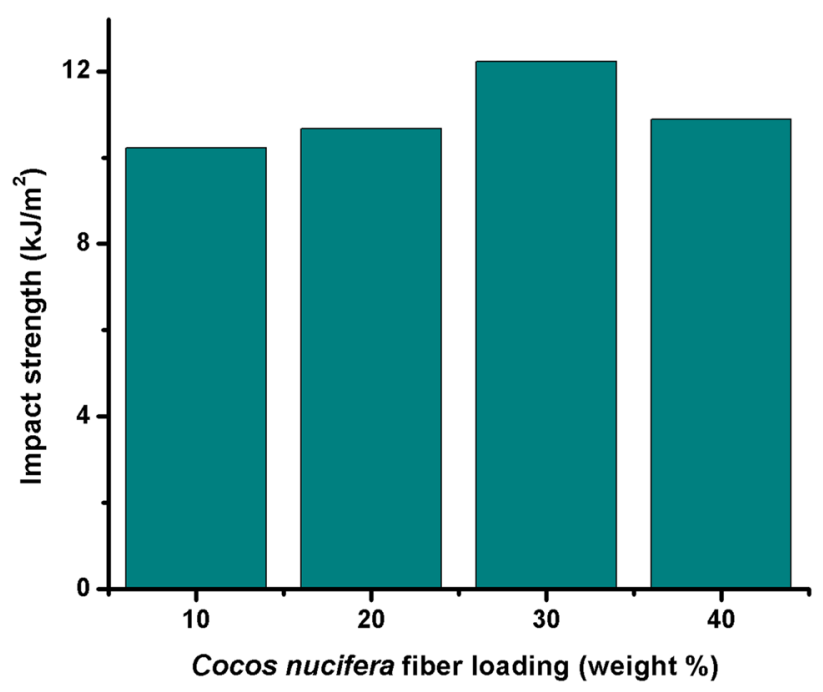

Fig. 3 Impact strength of Cocos nucifera fibers reinforced composites

a level, the properties dive. The impact strength values of the composites containing different fiber loading are shown in Fig. 3. Similar kind of values are reported for Kenaf bast fibers reinforced polyester composites with a maximum impact strength for $10 \mathrm{wt} \%$ of kenaf bast fibers [10].

\subsubsection{Morphological analysis}

The morphology of the fractured samples is viewed by SEM to study the failure mechanism of the composites. It can be noticed from Fig. 4a, that the failure of the composite samples ( $10 \mathrm{wt} \%$ fiber loading) is due to the resin rich region where there are not enough amounts of fibers to carry the load. Composites filled with low fiber loading present an increase in matrix rich region and as a result of the paucity of the fibers, there is an uneven stress distribution leading to the failure of the composite [20]. On the contrary, high fiber loading displays fiber rich region restrained in matrix. The internal cracks, pores, voids present in the fractured composites can be seen. This is associated with high moisture uptake of 

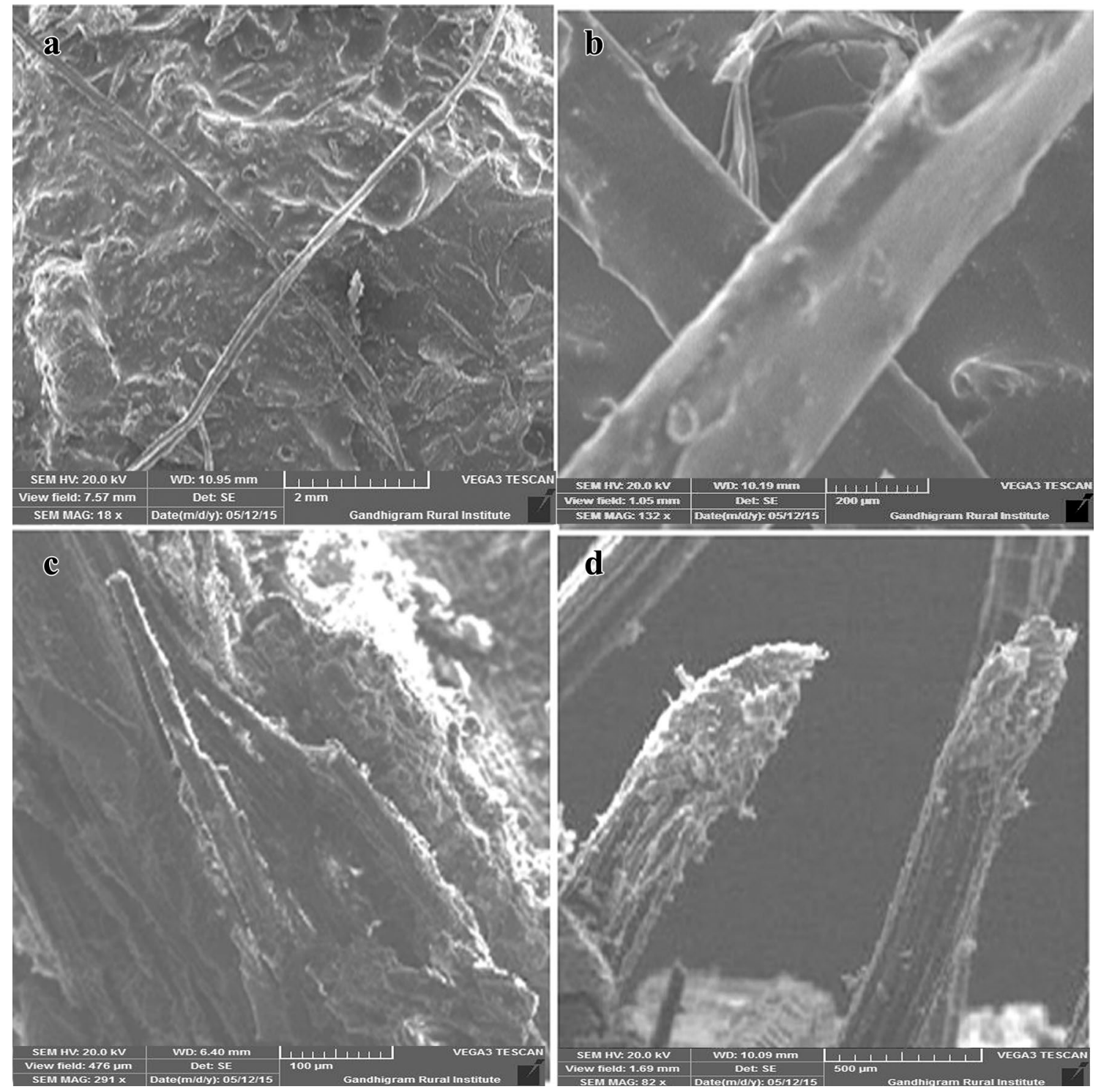

Fig. 4 Morphological analysis of the fractured Cocos nucifera composite sample

cellulosic fibers at high fiber loading [13]. Also seen is the reasonably smooth surface of the fibers which indicates weak adhesion between the matrix and reinforcement. Higher mechanical strengths can be attained when the surface of the fibers are rough which could increase the bonding strength between the fiber and matrix through mechanical interlocking leading to better mechanical properties. The random fiber orientation is also clearly seen in Fig. 4b. Microscopic image in Fig. 4c shows the dislocation of the fibers from the matrix due to shear force which is the reason for the non-catastrophic damage. Figure $4 \mathrm{~d}$ shows the broken tip of the fiber exhibiting necking phenomenon with reduced cross section confirming the ductile nature or the extensible property of the fiber due to its increased percent elongation on the application of load.

\subsection{Studies on Luffa cylindrica fibers reinforced composites}

\subsubsection{Flexural strength}

The flexural strength of the Luffa cylindrica fibers reinforced composites is determined using the 3-point flexural test. The results show that there is a linear relationship between the fiber loading and the flexural strength. Incorporation of the fibers in the matrix reinforces the matrix and leads to better mechanical properties. The rationale behind this kind of performance is the intrinsic characteristic of these 


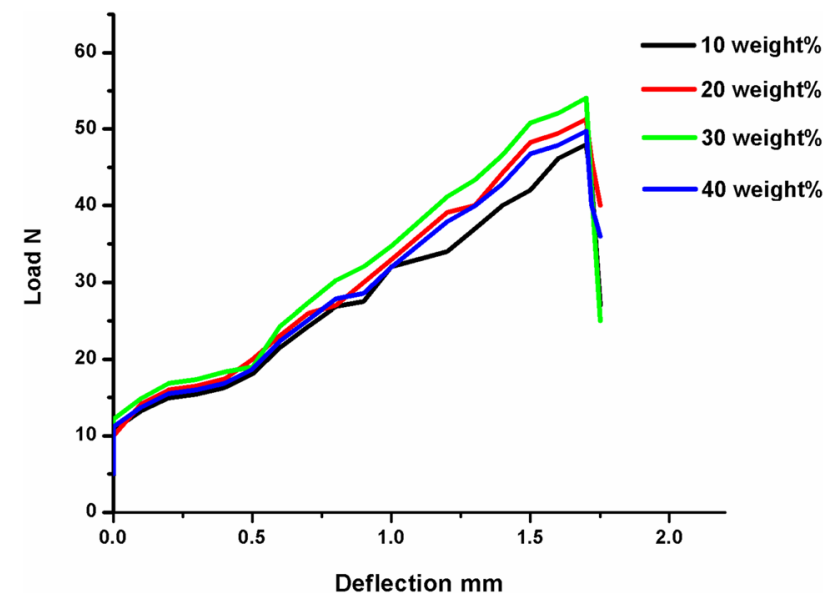

Fig. 5 Load versus Deflection sample curve for different wt\% of Luffa cylindrica reinforced composites

fibers with considerable cellulose content and crystalline index. These fibers in view of their unique and distinguishable natural vascular system can endure relatively stronger loads than other natural fibers [14]. The flexural strength of the composites increases from $10 \mathrm{wt} \%$ fiber loading to $30 \mathrm{wt} \%$ of fibers and the corresponding values are $26.67 \pm 0.61 \mathrm{MPa}, 28.56 \pm 0.67 \mathrm{MPa}$ and $30 \pm 0.46 \mathrm{MPa}$ respectively. A drop in the flexural strength values is seen when $40 \mathrm{wt} \%$ fibers loading is made and the flexural strength value is $27.67 \pm 0.47 \mathrm{MPa}$. This is due to the weak interface that exists between the matrix and fiber on account of increased fiber to fiber contact, where the stress could not be transferred in an even manner $[22,23]$. Similar kind of results is obtained for polymer composites reinforced using Calotropis procera fibers, sisal fibers, chicken feather fibers and Grewia serrulata composites [11, $12,21,28]$. Based on the current study, it is found that the composites could withstand a maximum load of $54 \mathrm{~N}$ for $30 \mathrm{wt} \%$ of fiber loading.

The Load versus Deflection curve obtained for various fiber loadings of the Luffa cylindrica fibers reinforced composite is illustrated in the Fig. 5. Initially, the curve for $30 \mathrm{wt} \%$ fiber loading shows a knee like pattern where there is small increase in deflection than the load applied which is little below $20 \mathrm{~N}$. Later, the curve portrays a linear behaviour with increasing deflection for increase in the load applied. The behaviour continues till the composite specimen achieves the maximum load and breaks eventually. The failure of the sample occurred in an abrupt manner denoting that the failure is due to flexural failure mode which has occurred both in the top and bottom layer of the specimen [29]. This shows the brittle nature of the composite exhibiting a catastrophic damage.

This linear behaviour is due to the inherent structure of the fiber which is a naturally formed vascular system
Table 4 Flexural strength of the Luffa cylindrica fibers reinforced composites

\begin{tabular}{lll}
\hline $\begin{array}{l}\text { Weight percent- } \\
\begin{array}{l}\text { age of unsaturated } \\
\text { polyester resin }\end{array}\end{array}$ & $\begin{array}{l}\text { Weight percentage } \\
\text { of Luffa cylindrica } \\
\text { fibers }\end{array}$ & $\begin{array}{l}\text { Flexural strength of } \\
\text { the composites (MPa) }\end{array}$ \\
\hline 90 & 10 & 26.67 \\
80 & 20 & 28.56 \\
70 & 30 & 30.00 \\
60 & 40 & 27.67 \\
\hline
\end{tabular}

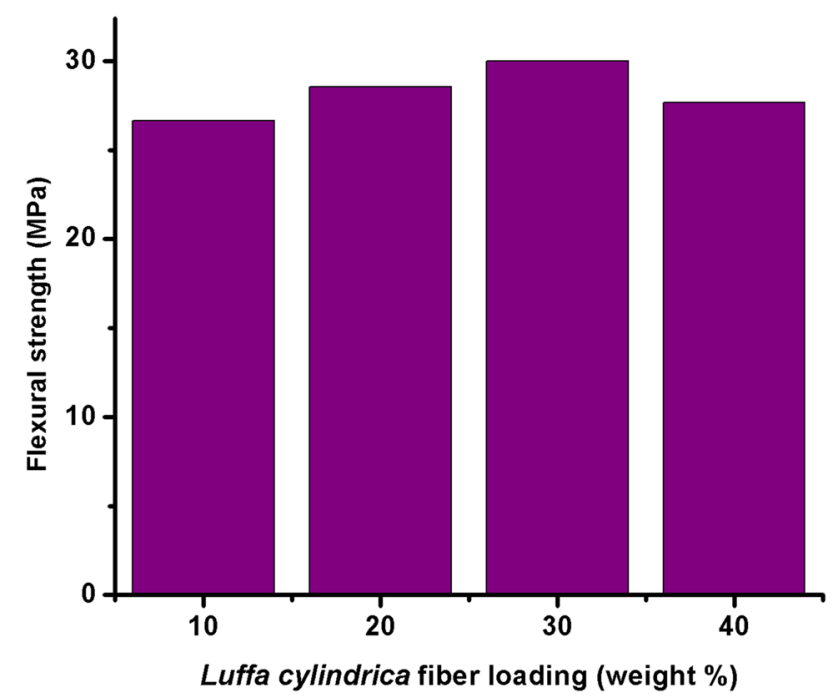

Fig. 6 Flexural strength of Luffa cylindrica fibers reinforced composites

of the fruit. When compared with the curve obtained for the Cocos nucifera fibers, the deflection is meager in this case, which is due to the less percent elongation of the Luffa cylindrica fibers. It is noteworthy to connote that the area under the curve is smaller than that of Cocos nucifera composites, implying that these fibers are stronger. This may be attributed to the presence of high crystallinity index and cellulose content of the Luffa cylindrica fibers [14]. Flexural behaviour of Calotropis procera bast fibers reinforced polyester composites fabricated by handlayup technique increase linearly with fiber addition accedes the current research with optimum mechanical properties obtained at $40 \mathrm{wt} \%$ of fibers [28].

The Luffa cylindrica fibers reinforced composites with $10,20,30$ and 40 fiber $w t \%$ of fiber loading exhibit maximum load bearing capacity ranging between 48 and $54 \mathrm{~N}$. The flexural strength values of the composites are shown in Table 4 and Fig. 6. 


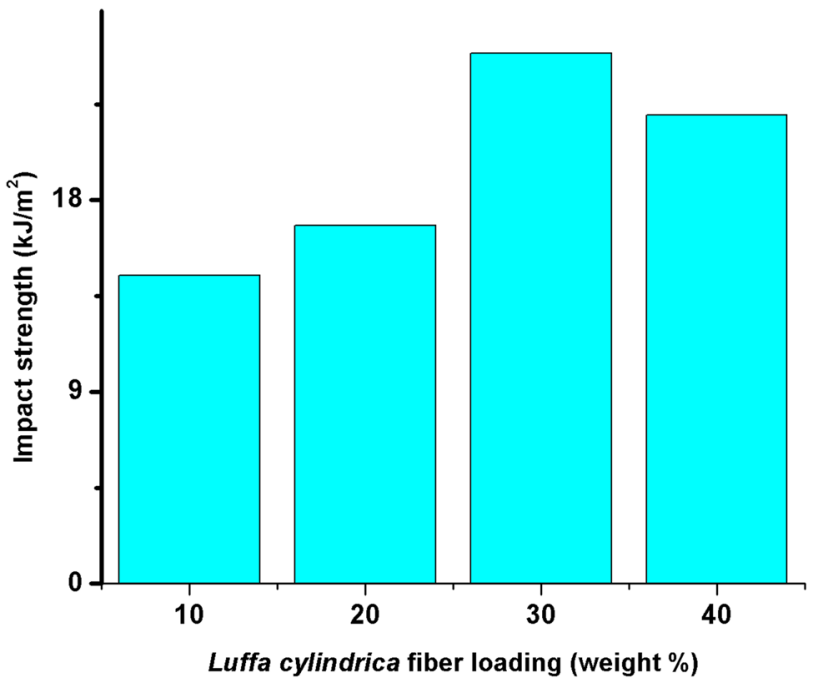

Fig. 7 Impact strength of Luffa cylindrica reinforced composites

Table 5 Impact strength of Luffa cylindrica reinforced composites

\begin{tabular}{lll}
\hline $\begin{array}{l}\text { Weight percentage of } \\
\text { unsaturated polyester } \\
\text { resin }\end{array}$ & $\begin{array}{l}\text { Weight percentage of } \\
\text { Luffa cylindrica fibers }\end{array}$ & $\begin{array}{l}\text { Impact strength } \\
\text { of the composites } \\
\left(\mathrm{kJ} / \mathrm{m}^{2}\right)\end{array}$ \\
\hline 90 & 10 & 14.44 \\
80 & 20 & 16.81 \\
70 & 30 & 24.88 \\
60 & 40 & 22.00 \\
\hline
\end{tabular}

\subsubsection{Impact strength}

The impact strength of the composite depends on interlaminar and interfacial action between the fiber and matrix and is affected by the type of reinforcing fibers, fiber and matrix interface, constructional geometry of the composites [30]. It is reported that weaving pattern of the fibers plays an important role in the determination of impact strength of the composite [31]. In this present study, the impact strength of the composites increases on increasing the wt $\%$ of fibers. The impact values of the composites in $\mathrm{kJ} / \mathrm{m}^{2}$ are $14.48 \pm 0.68,16.81 \pm 0.37,24.88 \pm 0.23$ and $22.00 \pm 0.44$ for $10 \%, 20 \%, 30 \%$ and $40 \%$ fiber loading respectively as shown in Fig. 7 and Table 5. Similar kind of results is obtained for the hybrid composites reinforced with fruit fibers composites [27]. This shows that the increase in impact strength may be due to the resemblance of the natural Luffa cylindrica fibers as woven mat which is unique of its kind [14]. Hence this unique and uniform arrangement could be the reason for the increased impact strength of the composites.

In case of natural fibers with random orientation, the dispersion of the fibers in the matrix may not be as good as this special unique network of fibers (natural mat). Hence the inclusion of the Luffa cylindrica fibers increases the impact strength of the composite. Low strength polyester matrix, on inclusion of these fibers provides greater impact strength and the spongy nature of the fiber vascular system could be attributed to this behaviour. Higher fiber loading causes fiber agglomeration, fiber entanglement and leads to failure of the composites. It has been reported that the layering pattern do not pronounce significant strength on the impact strength of the composite and for woven pattern, high impact strength of $23 \mathrm{~kJ} / \mathrm{m}^{2}$ is obtained in their study. It is agreeing well with the current study.

\subsubsection{Morphological analysis}

In order to find the energy absorption phenomenon in the sample, the micro-structure of the fractured specimen is studied. Fiber fracture, crack and tearing are the fracture mechanisms that can be noticed during impact loading in case of natural fiber composites. Fiber fracture shows the brittle failure of the composites.

In case of fractured samples, there is no fiber pull out, which means that there is a good interfacial adhesion between the matrix and reinforcement. Moreover, the broken ends of the fibers show the presence of matrix at the ends as seen in the Fig. 8a. This confirms that there is a good wettability of the fibers by the matrix. The presence of resin rich surface on the surface of the fractured sample, around the fibers restricts the sliding motion of the fibers by shearing action at the interface. The presence of river marks on the fractographs shows greater capacity of energy absorption by crack pinning mechanism [32].

In composite materials having weak interfacial bonding between fiber and matrix, the crack propagation through the interface between matrix and fiber, causes debonding resulting in increased energy absorption which is shown in the Fig. 8b. The morphology of the fractured sample show strands of fibers which are not completely restrained by the matrix. The random orientation of the fibers could also be noticed. The failure of reinforced composites could be due to presence of weak points where the cellulosic fibers break due the load leading to the development of the crack which continues and fractures. The weaker cellulose fibrils act as flaw and cracks, and then they propagate to the remaining intact reinforcement, leading to complete rupture of the composites. SEM analysis in Fig. $8 \mathrm{c}$, d shows the ends of broken fibers which indicate the brittle nature of the composite samples unlike Cocos nucifera fibers reinforced composites that exhibit reduced cross section area. Thus it is clear that the damage mechanism of these composites is through flexural failure with sudden and 

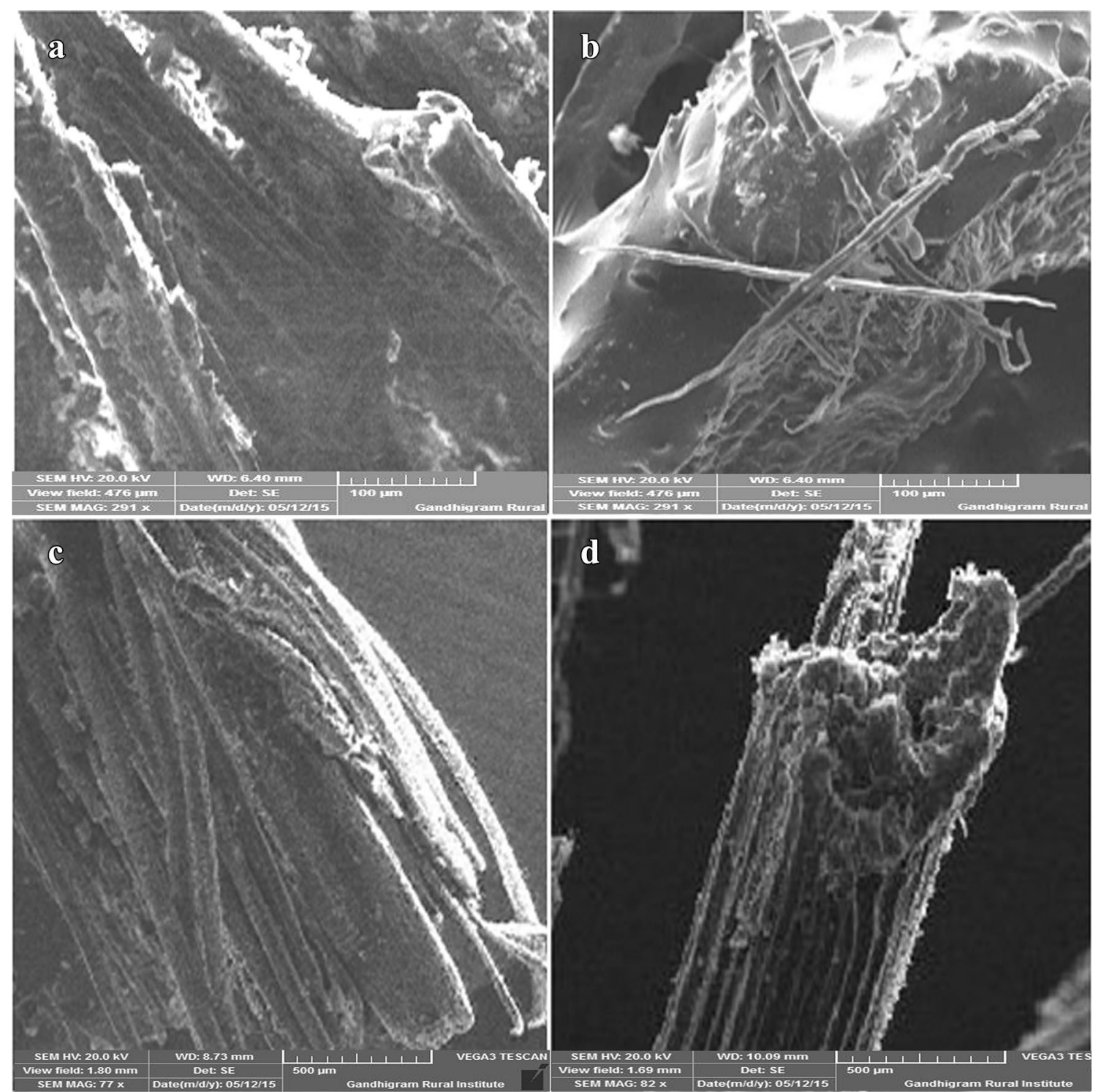

Fig. 8 Morphological analysis of fractured Luffa cylindrica composite sample

catastrophic nature and the fibers do not undergo elongation [19].

From the above discussion, the novelty presented in this study is the response of the composite samples upon mechanical loading. Even though, both the Cocos nucifera fibers reinforced composites and Luffa cylindrica fibers reinforced composites exemplify best possible mechanical properties at $30 \mathrm{wt} \%$ fiber loading, the difference lies in the way that these composite samples fail. Cocos nucifera composites fail exhibiting ductile failure after a steady elongation as against the Luffa cylindrica composites that fail abruptly exhibiting brittle failure as corroborated from their respective SEM images. The fiber structure is a major determinant for this behavior. Low lumen diameter fortifies Luffa cylindrica fibers to carry more loads without bending/stretching unlike the Cocos nucifera fibers. This mechanical behaviour can help in designing composites for specific applications where mode of failure of composites is a major concern so that early and or unprecedented failures can be avoided. This is the native behaviour of the composites reinforced with these lignocellulosic fibers. However, fiber modification studies such as mercerization, silane, hydroxyl treatment, permanganate treatment can be employed to improve the mechanical properties of composites as there would be an intact interfacial adhesion between the fibers and matrix [33]. 


\section{Conclusion}

This study summarizes the effect of fiber loading on the flexural and impact strength of the Cocos nucifera fibers reinforced composites and Luffa cylindrica fibers reinforced composites. Results prove that the optimum mechanical properties are obtained for $30 \mathrm{wt} \%$ of the fibers for both the composites. The mechanical properties increase with increase in fiber loading till $30 \mathrm{wt} \%$ and a decline in the values are noticed beyond it. The results suggest that the Cocos nucifera fibers reinforced composites show ductile failure and they are tough. On the contrary, Luffa cylindrica fibers reinforced composites exhibit brittle failure and are strong. Hence it can be concluded that, based on the type of application and need, the reinforcement can be selected.

Acknowledgements The authors are thankful to the retired Tamil Nadu State Government Forest Engineering Division Selection Grade Senior Draughting Officer, Mr. A. Balasubramanian, for his kind support in fiber extraction and in sample preparation.

\section{Compliance with ethical standards}

Conflict of interest The authors declare that they have no conflict of interest.

\section{References}

1. Nunna S, Chandra PR, Shrivastava S, Jalan AK (2012) A review on mechanical behavior of natural fiber based hybrid composites. J Reinf Plast Compos 31:759-769

2. NagarajaGanesh B, Ganeshan P, Ramshankar P, Raja K (2019) Assessment of natural cellulosic fibers derived from Senna auriculata for making light weight industrial biocomposites. Ind Crops Prod 139:111546

3. Hassan A, Salema AA, Ani FN, Bakar AA (2010) A review on oil palm empty fruit bunch fiber-reinforced polymer composite materials. Polym Compos 31:2079-2101

4. Yoganandam K, Ganeshan P, NagarajaGanesh B, Raja K (2019) Characterization studies on Calotropis procera fibers and their performance as reinforcements in epoxy matrix. J Nat Fibers. https://doi.org/10.1080/15440478.2019.1588831

5. Ganesh BN, Rekha B (2013) A comparative study on tensile behaviour of plant and animal fiber reinforced composites. Int J Innov Appl Stud 2(4):645-648

6. Pothan LA, Oommen Z, Thomas S (2003) Dynamic mechanical analysis of banana fiber reinforced polyester composites. Compos Sci Technol 63(2):283-293

7. NagarajaGanesh B, Muralikannan R (2016) Physico-chemical, thermal and flexural characterization of Cocos nucifera fibers. Int J Polym Anal Charact 21:244-250

8. Dhakal HN, Zhang ZY, Richardson MOW (2007) Effect of water absorption on the mechanical properties of hemp fiber reinforced unsaturated polyester composites. Compos Sci Technol 67:1674-1683
9. NagarajaGanesh B, Murali Kannan R (2015) Mechanical behaviour of agricultural residue reinforced composites. Sci Rev $1: 1-4$

10. Ishak MR, Leman Z, Sapuan SM et al (2010) Mechanical properties of kenaf bast and core fiber reinforced unsaturated polyester composites. IOP Conf Ser Mater Sci. Eng 11:012006

11. Sreekumar PA, Joseph K, Unnikrishnan G et al (2007) A comparative study on mechanical properties of sisal-leaf fiberreinforced polyester composites prepared by resin transfer and compression moulding techniques. Compos Sci Technol 67:453-461

12. Mahesha GT, Satish SB, Vijaya KM, Bhat KS (2016) Preparation of unidirectional Grewia serrulata fiber-reinforced polyester composites and evaluation of tensile and flexural properties. J Nat Fibers 13(5):547-554

13. Dabade BM, Reddy GR, Rajesham S et al (2006) Effect of fiber length and fiber weight ratio on tensile properties of sun hemp and palmyra fiber reinforced polyester composites. J Reinf Plast Compos 25:1733-1738

14. NagarajaGanesh B, Muralikannan R (2016) Extraction and characterization of lignocellulosic fibers from Luffa cylindrica fruit. Int J Polym Anal Charact 21:259-266

15. Bourmaud A, Morvan C, Bouali A, Placet V, Perre P, Baley C (2013) Relationships between micro-fibrillar angle, mechanical properties and biochemical composition of flax fibers. Ind Crops Prod 44:343-351

16. Ververis C, Georghiou K, Christodoulakis N, Santas P, Santas R (2004) Fiber dimensions, lignin and cellulose content of various plant materials and their suitability for paper production. Ind Crops Prod 19:245-254

17. Tutus A, Deniz I, Eroglu H (2004) Rice straw pulping with oxide added soda-oxygen-anthraquinone. Pak J Biol Sci 7:1350-1354

18. Sharma M, Sharma CL, Kumar YB (2013) Evaluation of fiber characteristics in some weeds of Arunachal Pradesh, India for pulp and paper making. Res J Agric For Sci 1:15-21

19. Alamri H, Low IM (2012) Mechanical properties and water absorption behaviour of recycled cellulose fibre reinforced epoxy composites. Polym Test 31:620-628

20. Vinayagamoorthy R, Rajeswari N (2014) Mechanical performance studies on Vetiveria zizanioides/Jute/glass fiber-reinforced hybrid polymeric composites. J Reinf Plast Compos 33:81-92

21. NagarajaGanesh B, Sugumaran P, Sridhar R (2012) Mechanical properties of rice straw and chicken feather fibers. Int J Compos Mater Manuf 3(2):22-26

22. Abdul Khalil HPS, Noorshashillawati Azura M, Issam AM, Said MR, Mohd Adawi TO (2008) Oil palm empty fruit bunches (OPEFB) reinforced in new unsaturated polyester composites. J Reinf Plast Compos 27:1817-1826

23. Ibrahim H, Farag M, Megahed H, Mehanny S (2014) Characteristics of starch-based biodegradable composites reinforced with date palm and flax fibers. Carbohydr Polym 101:11-19

24. Fuqua MA, Huo S, Ulven CA (2012) Natural fiber reinforced composites. Polym Rev 52:259-320

25. Rong MZ, Zhang MQ, Lui Y, Yang G, Zeng HM (2001) The effect of fiber treatment on the mechanical properties of unidirectional sisal reinforced epoxy composites. Compos Sci Technol 61:1437-1447

26. Pothan LA, Thomas S, Neelakantan NR (1997) Short banana fiber reinforced polyester composites: mechanical, failure and aging characteristics. J Reinf Plast Compos 16(8):744-765

27. NagarajaGanesh B, Muralikannan R (2016) Comprehensive characterization of lignocellulosic fruit fibers reinforced hybrid polyester composites. Int J Mater Sci Appl 5(6):302-307

28. Yoganandam K, NagarajaGanesh B, Ganeshan P, Raja K (2019) Thermogravimetric analysis of Calotropis procera fibers and their 
influence on the thermal conductivity and flammability studies of polymer composites. Mater Res Express 6:105341

29. Egusa S (1990) Anisotropy of radiation-induced degradation in mechanical properties of fabric-reinforced polymer-matrix composites. J Mater Sci 25:1863-1871

30. Joseph PV, Mathew G, Joseph K, Thomas S, Pradeep P (2003) Mechanical properties of short sisal fiber-reinforced polypropylene composites: comparison of experimental data with theoretical predictions. J Appl Polym Sci 88:602-611

31. Alavudeen A, Rajini N, Karthikeyan S, Thiruchitrambalam M, Venkateshwaren N (2015) Mechanical properties of banana/kenaf fiber-reinforced hybrid polyester composites: effect of woven fabric and random orientation. Mater Des 66:246-257
32. Idicula M, Joseph K, Thomas S (2010) Mechanical performance of short banana/sisal hybrid fiber reinforced polyester composites. J Reinf Plast Compos 29:12-29

33. Ganesh BN, Muralikannan R (2015) Tensile behavior of alkali treated natural fiber reinforced hybrid composites. Int J Appl Eng Res 10(28):20830-20835

Publisher's Note Springer Nature remains neutral with regard to jurisdictional claims in published maps and institutional affiliations. 